Cell Research(1993),3, 131-139

\title{
Cytoskeletal arrangement and its intercellular connec- tion in wheat young leaf cells
}

\author{
WEI X IANGYUN, LINGCHENG JIAN ${ }^{1}$ \\ Institute of Botany, Academia Sinica, Beijing 100044, \\ China.
}

\begin{abstract}
By using the techniques of partial digestion of cell wall and selective extraction, we examined the cytoskeleton of wheat young leaf cells under scanning electron microscope(SEM). A 3-dimensional cytoskeletal system, showing some new features, was observed. The cortical network located beneath the cross wall was an anastomosing organization. The association of nucleus with the cell wall by some skeletal filaments was also found. It is noticeable that there were cytoskeletal filaments, which passed through cell wall and connected together with cytoskeletal arrays of adjacent cells. Thus, it is possible that an integral skeletal network existed within the young leaf tissue of wheat.
\end{abstract}

Key words: cytoskeleton, intercellular connection, scanning electron microscopy, wheat.

\section{INTRODUCTION}

With the aid of electron microscopy, microtubules were found in plant cells by Ledbetter and Porter[1] and in animal cells by Slantherback[2] in 1963. Since then, cytoskeleton became one of the front fields in cell research, and many important findings have been obtained, contributing a great deal to the development of cell biology[3]. However, some important biological structures, especially protein filaments, may be obscured by using the conventional epoxy-embedding medium[4,5]. Furthermore, ultrathin section technique can reveal only 2 -dimensional views, so it is difficult to explore the exact organization of whole cytoskeleton. Although immunofluorescence microscopy is useful for the study of overall distribution of some

1. Corresponding author 
cytoskeletal arrangement in wheat cells

proteins within cell, the resolution provided by the light microscope restricts the visualization of detail structural organization. However, with the advent of new techniques, such as extraction with detergents [6] and whole mount preparation[5,6], this problem has been overcome to a great extent. By means of these techniques, a lot of exquisite micrographs were obtained, especially in the research on animal cytoskeleton[5,7,8], leading to a better interpretation of the distribution and structure of cytoskeleton in cells. Unfortunately, the effectiveness of the selective extraction technique is limited in plant cells due to their rigid cell wall. So it has been successful only in wall-less plant cells, such as protoplasts[7,9].

Previously, we have studied the cytoskeleton arrangement of wheat leaf cells by the use of immunofluorescent microscopy and transmission electron microscopy of negatively stained protoplast ghosts and ultrathin sections[10,11]. In the present experiments, using partial digestion of cell wall combined with selective extraction, we found some new features of cytoskeletal arrangement in wheat leaf cells.

\section{MATERIALS AND METHODS}

\section{Wheat seedling culture}

Seeds of winter wheat ( Triticum aestirum L. cv. Zhengzhou 39-1) were sown on wet filter paper in a Petri dish and cultured at $25^{\circ} \mathrm{C}$ in a $12 \mathrm{~h}$ light $/ 12 \mathrm{~h}$ dark cycle until shoots grown to about 1 cm in length.

\section{Prefixation}

Shoots were cut off at the bottom, then prefixed at room temperature for 20 rain, $1 \mathrm{~h}$ or $24 \mathrm{~h}$ with a prefixation solution (1.4\% glutaraldehyde $\mathrm{v} / \mathrm{v}, 0.8 \%$ Triton X-100 v/v, $10 \%$ dimethylsulfoxide in $50 \mathrm{~m} M$ phosphate buffer, $\mathrm{pH}$ 6.8, mainly according to the method of Sakiyama [12]).

\section{Partial digestion of the cell wall}

The $4 \mathrm{~mm}$ bottom segments of shoots were cut off and used. After gently washed with distilled water to remove the residual cytoplasm of the broken cells, the samples were digested in 3 steps: First, the samples were treated in 3\% cellulase (Onozuka R-10, Japan) in $200 \mathrm{~m} M$ mannitol for about $30 \mathrm{~min}$ at $25^{\circ} \mathrm{C}$. Second, after washing gently with $200 \mathrm{mM}$ mannitol 3 times, they were treated in 1\% pectinase (Koch-Light Laboratories Ltd, England) in $200 \mathrm{~m} M$ mannitol for $30 \mathrm{~min}$ at $25{ }^{\circ} \mathrm{C}$. Third, after washing gently as above, they were treated in $3 \%$ cellulase again as in first step for $40 \mathrm{~min}$. As a result, the cross wall located beneath the cutting face was removed, allowing the protoplasts together with the side wall visible.

\section{Extraction and fixation}

Extraction and fixation were done according to the method of Fey and Penman[3,10]. After partial digestion of cell wall, the samples were extracted with CSK buffer $(100 \mathrm{mM} \mathrm{KCl}, 3 \mathrm{mM}$ $\mathrm{MgCl}_{2}, 1.2 \mathrm{~m} M$ PMSF, $1 \%$ Triton X-100 v/v, $300 \mathrm{~m} M$ sucrose, $10 \mathrm{~m} M$ PIPES, $\mathrm{pH}$ 6.8). Some samples were also extracted with CSK-TD buffer (with $1 \%$ Tween 40 and $0.5 \%$ deoxycholate in CSK buffer but without Triton X-100). Following extraction, the samples were fixed again with $2.5 \%$ glutaraldehyde (v/v) in CSK buffer (without Triton X-100) at room temperature for $24 \mathrm{~h}$.

\section{Fracturing of the frozen samples}

After prefixation for $24 \mathrm{~h}$, the samples were washed with distilled water for three times, treated 
with 50\% dimethylsulfoxide for $30 \mathrm{~min}$, then cooled to liquid nitrogen temperature. The samples were fractured at this temperature. After that, the segments were thawed in distilled water at room temperature, then digested with $3 \%$ cellulase and $1 \%$ pectinase for $1 \mathrm{~h}$ at $22{ }^{\circ} \mathrm{C}$.

\section{Scanning electron microscopy}

After fixation, the samples were dehydrated through ethanol series, dried through the $\mathrm{CO}_{2}$ critical point, and then sputtercoated with platinum. The basal cells of the first leaf were examined under Hitachi S-800 and S-450 SEMs.

\section{RESULTS AND DISCUSSION}

\section{Cortical cytoskeletal network}

The cortical cytoskeletal networks have long been found in the cortex of plant cells. The networks mainly encompassed the cortical microtubules and microfilaments[14]. Several investigators have pointed out that the cortical microtubules adjacent to the side wall were usually perpendicular to or parallel to the long axis of the cell, and they were usually parallel with each other[12,15]. These cortical microtubules were thought to be related to the microfibrillar disposition of cell wall[12,15].

However, there have not been many works showing cortical cytoskeletal network located beneath the cross wall. By our method, the cortical network was found to lie just beneath the cross wall. It was a highly anastomosing network (Fig 1 . A-D). The ways in which these cytoskeletal filaments were organized were similar to what Schliwa et al. observed in animal cells[8]. The filaments of the network were mainly organized in 2 ways: First, lateral associations in a crossover pattern ( "X"-shaped), and "side-by-side" pattern. Second, "end-to-side" association in a "Y"-shaped pattern. In addition, a few connections which might be combinations of "X"-shaped and "Y"-shaped connections were also observed.

The diameter of the filaments was about $21 \mathrm{~nm}$. Since the slight coating of platinum on to the specimens could render the filaments a little bit thicker, and the drying procedure could also cause the specimens to shrink[16], the diameter measured from photographs might be somewhat different from that in living cells, but it did afford some useful information about the filaments.

\section{Cytoskeleton connecting nucleus with cell wall}

Because some part of side cell wall remained after partial digestion, it was found that the nucleus was connected with cell wall by cytoplasmic skeleton after being extracted with CSK-TD buffer (Fig 2 A,B). At a high magnification(Fig 2B), it was noticeable that these cytoskeletal filaments did not adhere simply to the cell wall, but extended into the residual cell wall and interwove with the wall components. Therefore, it is quite possible that these skeletal filaments did connect with cell wall in living cells, and the association observed was not an artifact. Powell et al.(1982) 
cytoskeletal arrangement in wheat cells

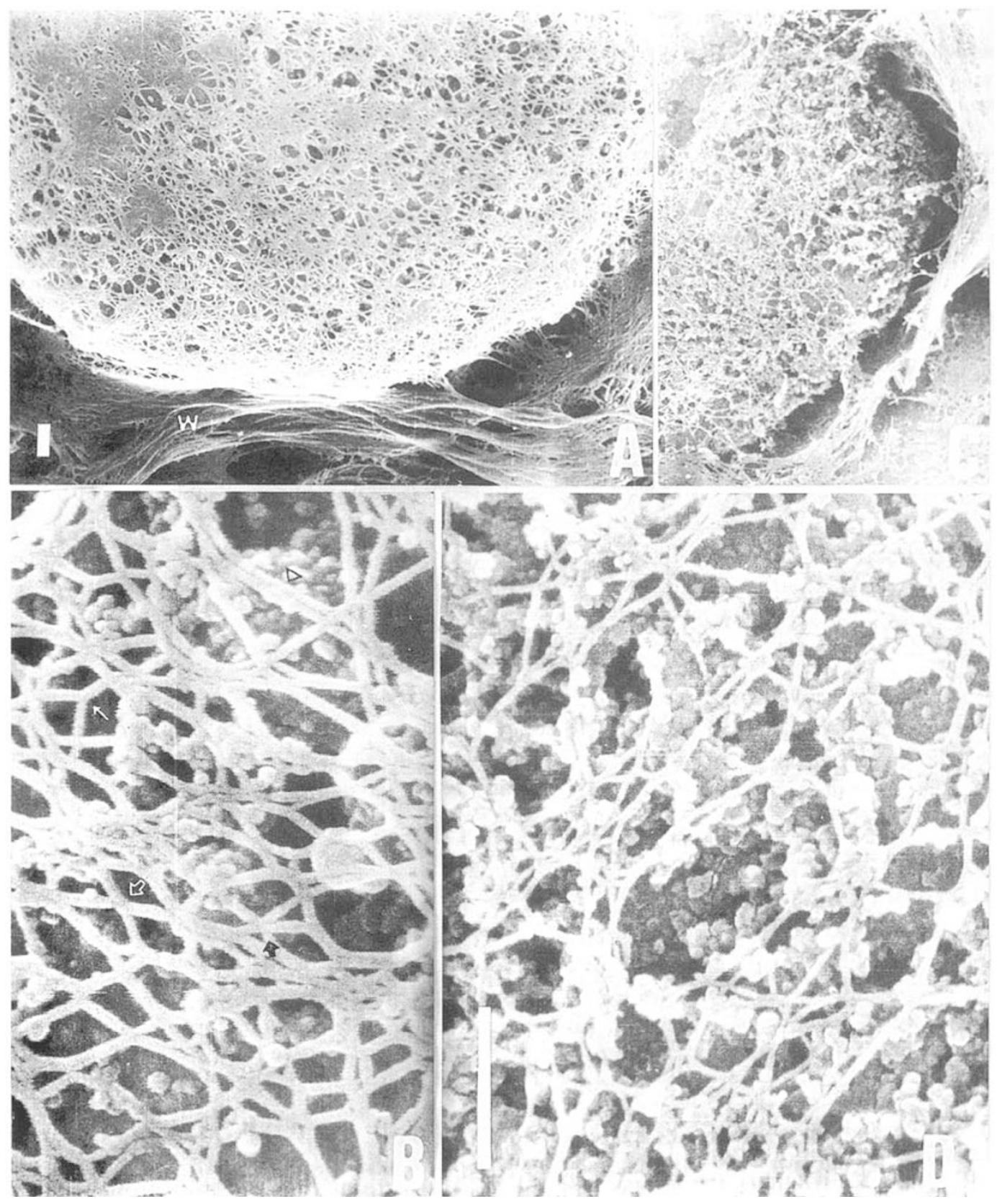

Fig 1. A-D. The specimens were prefixed for $1 \mathrm{~h}$ and extracted with CSK buffer. Bars: $0.5 \mu \mathrm{m}$.

A . The cortical cytoskeletal network and part of the side cell wall(W) can be observed.

B. Magnification of Fig 1A. "X” -shaped ( $\Uparrow)$, “Y”-shaped( $\uparrow$ ), and "side-byside" $(\triangle)$ associations of filaments are indicated.

C. Another view of the cortical cytoskeletal network.

D. Magnification of Fig 1C. 
Wei XY et al.

Fig 2 A-B. The specimens were prefixed for $20 \mathrm{~min}$ and extracted with CSK

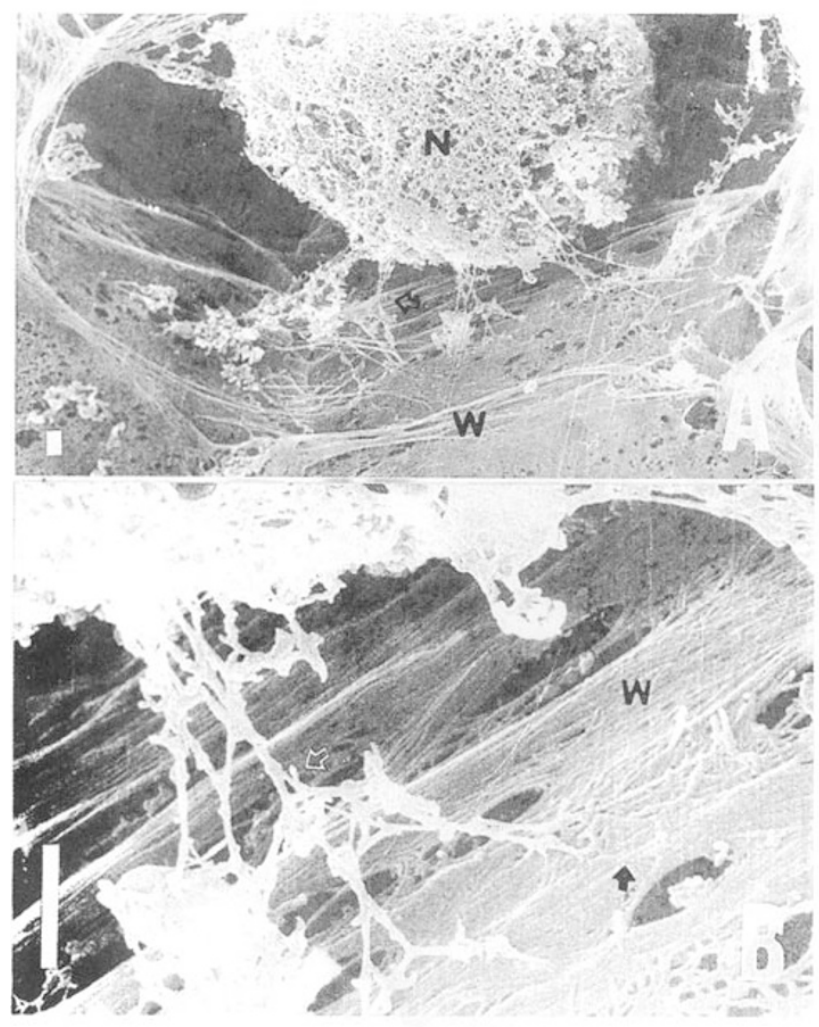

and CSK-TD

buffer. Bars: 0.5

$\mu \quad \mathrm{m}$

A. The cortical cytoskeletal

network and most cytoplasmic components were removed, leaving behind the $\operatorname{nucleus}(\mathrm{N})$ and a few cytoplasmic skeletal fila$\operatorname{ments}(\Uparrow)$. The filaments associate the nucleus with cell wall(W).

B. Magnification of Fig 2A. The filaments $(\Uparrow)$ interconnected the nucleus with cell wall(W), by extending them into residual cell wall and interweaving with wall components $(\uparrow)$.

observed that the nuclear-associated cytoskeleton stretched into the submembranous cell cortex[7]. However, these findings were observed in protoplasts, the exact relationships between the cytoskeleton and cell wall could not be clearly revealed.

Fey et al. had demonstrated that microtubules and microfilaments were not resistant to CSK-TD buffer, while the intermediate filaments were[5]. Although the samples in the present experiment had been prefixed for 20 min before extraction, this would not be long enough to render the cellular components resistant to CSKTD buffer. This could be evidenced demonstrated by the disappearance of many components, such as the cortical network after extraction with CSK-TD buffer. Thus, the filaments remained between cell wall and nucleus might be resistant to CSK-TD buffer, and were possibly intermediate filaments in nature.

In fact there were some evidences indicating the existence of intermediate filaments in plants. Dawso et al. had shown that the monoclonal antibody against an 
cytoskeletal arrangement in wheat cells
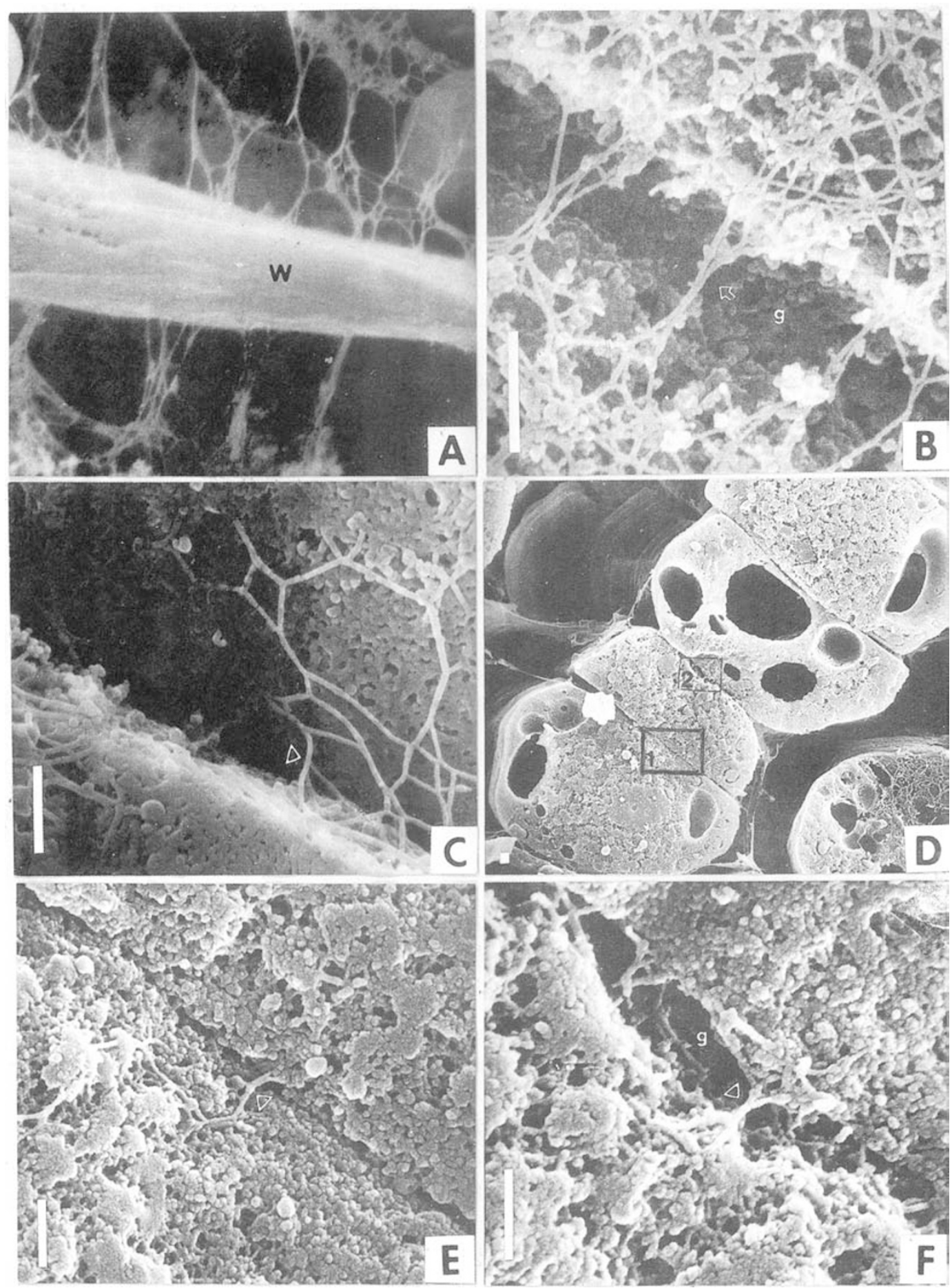
intermediate filaments antigen cross-reacted with protein in homogenates of carrot suspension cells and meristematic cells from onion root tips[17]. In 1985, Miller et al. obtained similar results in algae Chlamydomonas[18]. Later, Su et al., using immunogold labeling with monoclonal antibody of cytokeratin from animal cells, found a keratin intermediate filament-like system in maize protoplasts[9].

All these evidences supported the possibility that intermediate filaments did exist in plants. Therefore, the filaments discussed above were likely to be intermediate filament-like fibers, and they might act to fix the nucleus in a certain place within the cell by anchoring it to cell wall.

\section{Intercellular cytoskeletal connection between adjacent cells}

Fey et al. (1984) reported that in epithelial colonies of Madin-Darby Canine Kidney (MDCK) cells, the topography of cytoskeleton was relatively constant throughout the epithelial sheet. This indicated that in highly organized animal tissue, cytoskeleton in each cell may link with that of others, forming an integral network in the tissue[5]..

Does this phenomenon exist also within plant tissues? In our study, it was found that cytoskeletal arrays of adjacent cells may be connected together in wheat young leaf tissue.

It was observed that cytoskeleton in adjacent cells connected with the separating side wall nearly at the opposing sites (Fig 3A). From this findings, we got the impression that they might pass through the side wall and combined with the cytoskeletal arrays in adjacent cells. In order to verify this assumption, we prolonged the digestion time to partially remove the cell wall between adjacent cells. As a re-

Fig 3 A-B. $\triangleleft$ The specimens were prefixed for about $1 \mathrm{~h}$ and extracted with CSK buffer Bars: $0.5 \mu \mathrm{m}$.

A . The cytoskeletal arrays of the 2 adjacent cells connected to the separating side wall(W) at nearly opposing sites.

B . The cytoskeletal arrays of 2 adjacent cells were linked together by intercellular skeletal filaments $(\uparrow)$ which passed through the gap $(\mathrm{g})$ previously occupied by cell wall.

Fig 3C. $\triangleleft$ The specimens were prefixed for $24 \mathrm{~h}$ and extracted with CSK buffer. It was noticeable that there were skeletal filaments $(\triangle)$ going out of one cell and entering into an adjacent cell. Bar:0.5 $\mu \mathrm{m}$.

Fig 3 D-F. $\triangleleft$ The specimens were fractured at liquid nitrogen temperature, digested with cellulase and pectinase and extracted with CSK buffer. Bars: $0.5 \mu \mathrm{m}$.

D. Whole view of the fracture surface, showing sister cells and non-sister cells.

E. Magnification(l) of Fig $3 \mathrm{D}$. The cytoskeletal filament $(\triangle)$ interconnected one sister cell with the other one.

F. Magnification(2) of Fig 3D. Cytoskeletal filaments $(\triangle)$ going out of one nonsister cell and entering into another, straddling the gap(g) that was previously occupied by cell wall. 
cytoskeletal arrangement in wheat cells

result, these kinds of intercellular skeleton were actually found to be present passing through the gap left behind after the digestion of cell wall (Fig 3B,C). The phenomenon existed not only between sister cells which have undergone cytokinesis a short time before (Fig 3E), but also between non-sister cells (Fig 3F). In these 2 situations, it was noticeable that there were skeletal filaments which connected with the skeletal arrays of both adjacent cells (Fig 3B,C,E,F). This indicated that this kind of intercellular skeleton may be already there when the cell wall between sister cells was being formed, and may exist from then on. If this were true, their way of genesis might be similar to that of endoplasmic reticulum in plasmodesmata. However, the exact relationship between intercellular skeletal connection and interstitial canal remains unknown.

Electron microscopy has long been applied to plant cell research, but why such intercellular connection has not been definitely observed up to now? According to Penman and his colleagues[4], this ignorance may be due to the obscurity caused by embedding medium to biological structures. The definite chemical characteristics of these intercellular cytoskeletons, the way they pass through cell wall, the role they play in plant tissue and the possibility of their developmental change etc, all need further investigation.

\section{ACKNOWLEDGEMENTS}

Project supported by the National Nature Science Foundation of China. We were grateful to Mrs Sun Longhua for her technical assistance in photography work.

\section{REFERENCES}

[1] Ledbetter MC and Porter KR. A “microtubule” in plant cell fine structure. J Cell Biol 1963; 19:239-50.

[2] Slautterback DB. Cytoplasmic microtubules. J Cell Biol 1963; 18:367-88.

[3] Jian LC. Plant cytoskeleton. Chin Bull Bot 1991; 8:1-13.

[4] Capco CG, Krochmalnic G, Penman S. A new method of preparing embeddment-free section for transmission electron microscopy: application to the cytoskeletal framework and other threedimensional network. J Cell Biol 1984; 98:1878-85.

[5] Fey EG, Wan KM, Penman S. Epithelial cytoskeletal framework and nuclear matrix-intermediate filament scaffold: Three dimensional organization and protein composition. J Cell Biol 1984; 98: $1973-84$.

[6] Brown S, Levinson W, Spudich J. Cytoskeletal elements of chick embryo fibroblasts revealed by detergent extraction. J Supramol Struct 1976; 5:119-30.

[7] Powell A J, Peace GW, Slabas AR, Lloyd CW. The detergent resistant cytoskeleton of higher plant protoplast contains nucleus-associated fibrillar bundles in addition to microtubules. J Cell Sci 1982; 56:319-35.

[8] Schliwa M, Blerkom JV, Pryzwasky KB. Structural organization of the cytoplasm. Cold Spring Harbor Symposia on Quantitative Biology. 1982; 46:51-67.

[9] Su F, Gu W, Zhai Z. The keratin intermediate filament-like system in maize protoplasts. Cell Res 1990; 1:11-6. 
[10] Jian LC, Sun LH, Sun DL. Studies on the cortical microtubules in the leaf cells of wheat Triticum aestivum L. Acta Biol Exp Sin 1984; 17:149-59.

[11] Jian LC, Sun LH, Lin ZP. Studies on microtubules cold stability in relation to plant cold hardiness. Acta Bot Sin 1989; 31:737-41.

[12] Sakiyama M, Shibaoko H. Effect of abscisic acid on the orientation and cold stability of cortical microtubules in epicotyl cells of the dwarf pea. Protoplasma 1990;157:165-71.

[13] Penman S, Fulton A, Capco D, Zelev AB, Wittelsberger S, Tse CF. Cytoplasmic and nuclear architecture in cells and tissue: Form, function and mode of assembly. Cold Spring Harbor Symposia on Quantitative Biology 1982; 46:1013-28.

[14] Hepler PK, Patevitz BA. Microtubules and microfilaments. Ann Rev Plant Physiol 1974; 25:30962.

[15] Hardham AR, Gunning BES. Interpolation of microtubules into cortical arrays during cell elongation and differentiation in roots of Azolla pinnata. J Cell Sci 1979; 37:411-42.

[16] Tanaka K, Eitani R. Graphic explanation of scanning electron microscopy - Preparation of biological samples. Translated by Li Wenzheng and Ying Guohua. Science Press. 1984.pp94.

[17] Dawson P J, Hulme JS, Lloyd CW. Monoclonal antibody to intermediate filament antigen crossreacts with higher plant cells. J Cell Biol 1985; 100:1793-8.

[18] Miller CJ et al. Plant cytoskeletons contain intermediate filament-related proteins. Biochem Soc Trans 1985; 13:960-1.

Received 30-12-1991. Revised 17-5-1993. Accepted 18-5-1993 